\title{
Evaluation of serum cysteine-rich protein 61 levels in patients with coronary artery disease
}

\author{
Jingang Deng*,1, Xiaoxian Qian², Jianping $\mathrm{Li}^{1}$, Yanghua $\mathrm{Li}^{1}$, Yang $\mathrm{Li}^{1}$ \& Yijun Luo ${ }^{1}$ \\ ${ }^{1}$ Division of Cardiology, Shenzhen Tenth People's Hospital, Shenzhen, Guangdong, PR China \\ ${ }^{2}$ Division of Cardiology, The Third Hospital of Sun Yat-sen University, Guangzhou, Guangdong, PR China \\ * Author for correspondence: Tel.: + 86755 27548903; Fax: +86 755 27548173; dr.dengjingang@hotmail.com
}

\begin{abstract}
Aim: The aim is to evaluate serum cysteine-rich protein 61 (Cyr61) levels in patients with coronary artery disease (CAD). Patients \& methods: Serum Cyr61 levels were measured in 180 patients with CAD and 74 participants without CAD. Results: Serum Cyr61 levels were significantly higher in CAD patients. Patients with acute coronary syndrome showed significantly higher Cyr61 than those with stable angina pectoris. Serum Cyr61 levels in complex lesion group were significantly higher. Serum Cyr61 was positively correlated with Gensini score and C-reactive protein. Multivariable logistic regression analyses demonstrated that serum Cyr61 levels were independently correlated with the existence of CAD $(p=0.01)$. Conclusion: Our study suggested Cyr61 as a potential biomarker in characterizing CAD and therapeutic target for CAD.
\end{abstract}

First draft submitted: 7 November 2017; Accepted for publication: 2 January 2018; Published online: 18 January 2018

Keywords: atherosclerosis $\bullet$ coronary artery disease $\bullet$ C-reactive protein $\bullet$ Cyr61 • inflammation

Matricellular proteins are a group of secreted extracellular matrix-associated proteins which play a wide range of functions and roles including the dynamic changes in extracellular matrix and tissue remodeling at the sites of inflammation, tissue injury and repair as well as atherosclerosis [1-3]. Such proteins as osteopontin, thrombospondin, periostin and secreted protein acidic and rich in cysteine have been demonstrated in an important role in inflammation and pathohenesis or progression of atherosclerosis [3-8]. In recent years, a novel matricellular protein Cysteine-rich protein 61 (Cyr61, CCN1), identified as a product of immediate early gene in response to serum growth factors and high dynamically expressed and secreted matricellular protein, has emerged as multifunctional and inflammatory modulator in cellular signaling and behaviors $[3,9,10]$. The function of Cyr61 is mediated primarily via specific integrins binding and requiring heparin sulfate proteoglycans co-receptors on the cell surface, which regulate a wide range of cell type-dependent functions and processes including cell growth, adhesion, migration, differentiation and survival or death and participate in inflammation, neovascularization, wound healing and tissue remodeling as well as thrombosis and hemostasis [9-11].

The relationship of Cyr61 with vascular diseases was recently explored. In a rat carotid artery injury model, Cyr61 protein level was rapidly increased in the media and neointima of the injured vessels by day 4 postinjury and lasts for 4 weeks, while the knockdown of Cyr61 by siRNA significantly inhibited neointimal formation [12]. Furthermore, Cyr61 expression in aortic arteriosclerotic plaques of ApoE-deficient mice and in human arteriosclerotic lesions was significant elevated [13,14]. Immunohistochemical analysis of cardiac tissue specimens from individuals died of sudden cardiac death revealed that Cyr61 immunoreactivity was significantly associated with myocardial ischemia, interstitial edema and atheromatosis of coronary arteries [16]. However, serum level of Cyr61 and its significance in patients with coronary artery disease (CAD) has not been investigated until a recent study by Klingenberg et al. [49] published online after our first draft was submitted. Klingenberg et al. demonstrated Cyr61 as a novel early biomarker in reflecting myocardial injury that improves risk stratification in patients with acute coronary syndrome (ACS), but not evaluated serum Cyr61 levels and its significance in CAD and its subgroups compared with health participants as control. Based on these studies of Cyr61 in atherosclerosis, the present study aimed to evaluate the serum Cyr61 level and its association with severity of CAD in patients with CAD. 


\section{Methods}

\section{Study subjects}

This study was approved by the ethic committee of the authors' hospitals. Informed consent was obtained from each participant. A total of 180 patients (male 126 and female 54) with CAD at an average age of $62.25 \pm 10.36$ years were recruited. The clinical diagnoses of $\mathrm{CAD}$ in the patients were confirmed by coronary angiographic finding of any coronary arterial luminal stenosis at or more than $50 \%$ in diameter. All the patients were classified as stable angina pectoris (SAP, 78 patients), unstable angina pectoris (UAP; class II or III of Braunwald's classification, 62 patients) and acute myocardial infarction (AMI, 40 patients) according to their clinical diagnoses. Age- and gender-matched healthy volunteers $(n=74$, male 48 and female 26 ; age $62.39 \pm 9.48$ years) were randomly recruited in this study as the control (Ctrl) group. All the subjects in the Ctrl group did not show any CAD symptoms and history with normal ECG and ECG treadmill testing. Patients with other heart diseases, acute or chronic infection, tumors, autoimmune diseases, renal and hepatic diseases, anemia, peripheral or cerebrovascular vascular diseases, surgery or trauma within 3 months were excluded.

\section{Data \& blood sample collection}

Weight was measured in kilograms and height in meters. BMI was measured as weight $(\mathrm{kg}) / \mathrm{height}\left(\mathrm{m}^{2}\right)$. Blood pressures (BPs) were measured in a supine position. Smoking habits were recorded by questionnaire. Three milliliters venous blood was collected from each participant after a 12-h overnight fast. Blood samples from patients with UAP or AMI were taken immediately after admission. All the blood samples were centrifuged at $3000 \mathrm{rpm}$ at $4{ }^{\circ} \mathrm{C}$ for $10 \mathrm{~min}$. The serum were separated and stored at $-70^{\circ} \mathrm{C}$ for detection within 3 months.

\section{Coronary artery angiography \& Gensini score}

Diagnostic coronary angiography was performed in multiple views in all patients using standard Judkins femoral approach and techniques. Coronary stenotic lesion was divided into simple lesion defined as one coronary branch stenosis $\geq 50 \%$ and complex lesion defined as $>1$ coronary branches with stenosis $\geq 50 \%$. Gensini score [17], an index to reflect coronary stenotic severity in clinic, was calculated by two experienced cardiologists who were blinded to the clinical and laboratory data to evaluate the severity of coronary atherosclerotic lesions based on the angiographic results according to the standard method.

\section{Laboratory measurements}

Serum Cyr61 levels were measured using a commercially available ELISA kit (DRG Diagnostics, Marburg, Germany) according to the manufacturer's instruction. Blood glucose, lipids and other related indicators were also detected simultaneously with a Hitachi Automatic Biochemical Analyzer (Hitachi Co., Tokyo, Japan). Serum high sensitivity C-reactive protein (hs-CRP) levels were measured with the commercial ELISA kit (Dade Behring Diagnostics GmbH, Germany).

\section{Statistical analysis}

All the continuous variables with normal distributions are expressed as mean \pm standard deviation and analyzed by Student's t-test or the one-way analysis of variance test, continuous variables with skewed distributions are expressed as median and quartile ranges and analyzed by Mann-Whitney $U$ test. Categorical data were expressed as numbers or percentages and compared with $\chi^{2}$ test. Spearman coefficients were calculated to determine the correlation between biochemical parameters. Multivariable logistic regression models were used to evaluate the association of cardiovascular risk factors with CAD. Statistical analysis was done with SPSS version 17 except MedCalc software (z-test) used for comparison of receiver operating characteristic (ROC) curves of Cyr61 and hs-CRP. A p-value less than 0.05 was considered significant statistically.

\section{Results}

\section{Demographic characteristics of the study subjects}

The clinical and biochemical parameters of the study subjects are summarized in Table 1 . In the Ctrl group $(\mathrm{n}=74)$, 52 were male and 22 were female, the average age was $62.39 \pm 9.48$ years. In CAD group $(n=180), 132$ were male and 48 were female, the average age was $65.25 \pm 10.36$ years. There were no significant differences in age, gender, BMI and history of diabetes, and also no significant differences in high-density lipoprotein-cholesterol, white blood cell, platelets, glucose, blood urea nitrogen and serum creatinine between the Ctrl and CAD groups. However, 


\begin{tabular}{|c|c|c|c|c|c|}
\hline Variables & Ctrl $(n=74)$ & All CAD $(n=180)$ & SAP $(n=78)$ & UAP $(n=62)$ & AMI $(n=40)$ \\
\hline Age (years) & $62.39 \pm 9.48$ & $65.25 \pm 10.36$ & $65.42 \pm 9.62$ & $62.35 \pm 11.33$ & $64.18 \pm 11.54$ \\
\hline Male (n, \%) & $52(70.3)$ & $132(73.3)$ & $58(73.1)$ & $44(70.9)$ & $30(75)$ \\
\hline BMI $\left(\mathrm{kg} / \mathrm{m}^{2}\right)$ & $24.48 \pm 3.72$ & $26.28 \pm 4.85$ & $25.52 \pm 3.78$ & $23.12 \pm 2.98$ & $26.75 \pm 4.83$ \\
\hline Smoking (n) & 12 & $98^{*}$ & 38 & 36 & 24 \\
\hline HTN (n) & 15 & $101^{*}$ & 45 & 34 & 22 \\
\hline DM & 8 & $40^{*}$ & 18 & 13 & 9 \\
\hline $\mathrm{TG}(\mathrm{mg} / \mathrm{dl})$ & $147.65 \pm 38.93$ & $168.84 \pm 46.67^{\star}$ & $162.56 \pm 50.49$ & $155.26 \pm 43.57$ & $175.48 \pm 62.68$ \\
\hline $\mathrm{TC}(\mathrm{mg} / \mathrm{dl})$ & $170.38 \pm 41.52$ & $210.45 \pm 38.72^{*}$ & $196.73 \pm 48.86$ & $194.75 \pm 37.65$ & $208.45 \pm 52.45$ \\
\hline $\mathrm{HDL}-\mathrm{C}(\mathrm{mg} / \mathrm{dl})$ & $46.45 \pm 7.68$ & $43.84 \pm 6.86$ & $42.82 \pm 8.86$ & $44.23 \pm 7.34$ & $42.45 \pm 8.98$ \\
\hline LDL-C (mg/dl) & $113.45 \pm 27.55$ & $129.65 \pm 29.3^{*}$ & $124.3 \pm 26.6$ & $128.5 \pm 34.7$ & $130.42 \pm 31.46$ \\
\hline WBC $\left(10^{3} / \mu l\right)$ & $6.78 \pm 2.09$ & $7.38 \pm 1.88$ & $6.72 \pm 1.75$ & $9.24 \pm 2.68$ & $8.85 \pm 3.22$ \\
\hline Platelet $\left(10^{3} / \mu \mathrm{l}\right)$ & $221.75 \pm 65.53$ & $228.75 \pm 78.48$ & $216.65 \pm 72.45$ & $235.93 \pm 93.67$ & $235.05 \pm 88.89$ \\
\hline Uric acid (mg/dl) & $5.34 \pm 1.73$ & $6.96 \pm 2.65^{*}$ & $6.44 \pm 1.57$ & $7.38 \pm 2.45$ & $7.78 \pm 3.82$ \\
\hline Glucose $(\mathrm{mg} / \mathrm{dl})$ & $97.84 \pm 22.46$ & $115.33 \pm 24.56$ & $97.63 \pm 25.86$ & $113.72 \pm 21.86$ & $120.96 \pm 28.48$ \\
\hline BUN (mg/dl) & $11.37 \pm 4.72$ & $12.06 \pm 3.54$ & $12.64 \pm 5.78$ & $10.38 \pm 4.77$ & $13.75 \pm 6.22$ \\
\hline $\mathrm{Cr}(\mathrm{mg} / \mathrm{ml})$ & $1.14 \pm 0.36$ & $1.09 \pm 0.47$ & $1.13 \pm 0.24$ & $0.97 \pm 0.59$ & $1.24 \pm 0.56$ \\
\hline hs-CRP (mg/l) & $1.58 \pm 0.68^{*}$ & $6.05 \pm 3.78$ & $2.75 \pm 1.42$ & $7.60 \pm 2.37^{\star \star}$ & $10.1 \pm 3.2^{\star *}$ \\
\hline \multicolumn{6}{|c|}{$\begin{array}{l}{ }^{*} \text { Significance between Ctrl and CAD groups, } \mathrm{p}<0.05 ; \\
{ }^{* *} \mathrm{p}<0.001 \text { versus SAP. } \\
\text { AMI: Acute myocardial infarction; BMI: Body mass index; BUN: Blood urea nitrogen; CAD: Coronary artery disease; Cr: Serum creatinine; Ctrl: Control; DM: Diabetes mellitus; HDL- } \\
\text { C: High-density lipoprotein-cholesterol; hs-CRP: High sensitivity C-reactive protein; HTN: Hypertension; LDL-C: Low-density lipoprotein-cholesterol; SAP: Stable angina pectoris; TC: Total } \\
\text { cholesterol; TG: Triglyceride; UAP: Unstable angina pectoris; WBC: White blood cell. }\end{array}$} \\
\hline
\end{tabular}

Figure 1. Serum Cyr61 levels in each group. Serum Cyr61 levels in patients with CAD were significantly increased compared with those in Ctrl group, and serum Cyr61 levels in patients with UAP or AMI were significantly increased compared with those with SAP. AMI: Acute myocardial infarction; CAD: Coronary artery disease; Ctrl: Control; SAP: Stable angina pectoris; UAP: Unstable angina pectoris.

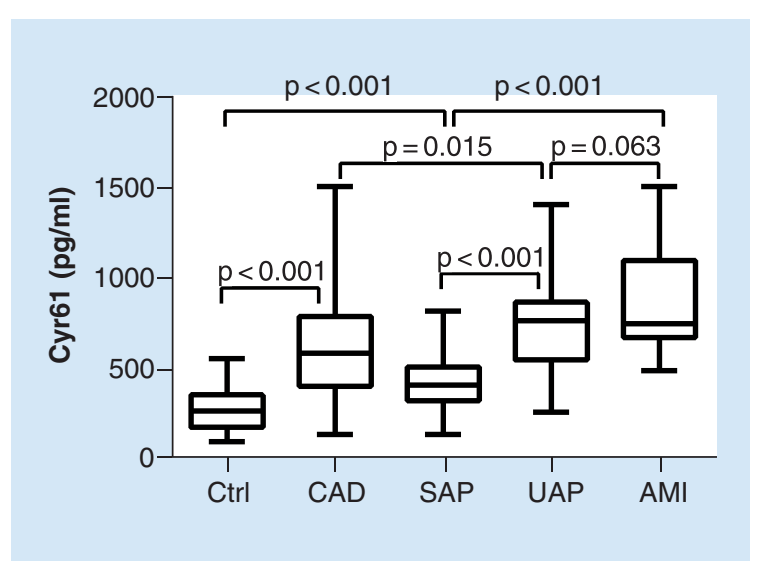

cigarette smoking, diabetes mellitus (DM) and hypertension (HTN) history, triglyceride, total cholesterol, lowdensity lipoprotein-cholesterol, hs-CRP and uric acid were higher significantly in CAD group compared with that in the Ctrl group.

\section{Serum Cyr61 levels in CAD \& subgroups}

The serum Cyr61 levels in the Ctrl and CAD groups were shown in Figure 1. Serum Cyr61 levels in patients with CAD were significantly elevated compared with those in the Ctrl group (621.30 \pm 283.72 vs $265.26 \pm 116.70 \mathrm{pg} / \mathrm{ml}$; $<0.001)$. To evaluate serum Cyr61 level changes in CAD types, all patients were grouped into three subgroups clinically: SAP, UAP and AMI. Compared with the serum Cyr61 level in SAP subgroup, serum Cyr61 levels in UAP $(729.58 \pm 247.15$ vs $415.08 \pm 143.33 \mathrm{pg} / \mathrm{ml}$; $<0.001)$ or AMI $(855.61 \pm 270.88$ vs $415.08 \pm 143.33 \mathrm{pg} / \mathrm{ml} ; \mathrm{p}<0.001)$ subgroups were significantly higher. Serum Cyr61 in AMI group was higher than in UAP one, but there was no statistic difference in serum Cyr61 levels between UAP and AMI subgroups. As ACS includes UAP and AMI, we also found that serum Cyr61 levels in ACS subgroup were significantly higher $(811.44 \pm 265.39$ vs $415.08 \pm 143.33 \mathrm{pg} / \mathrm{ml}$; $<<0.001)$. 


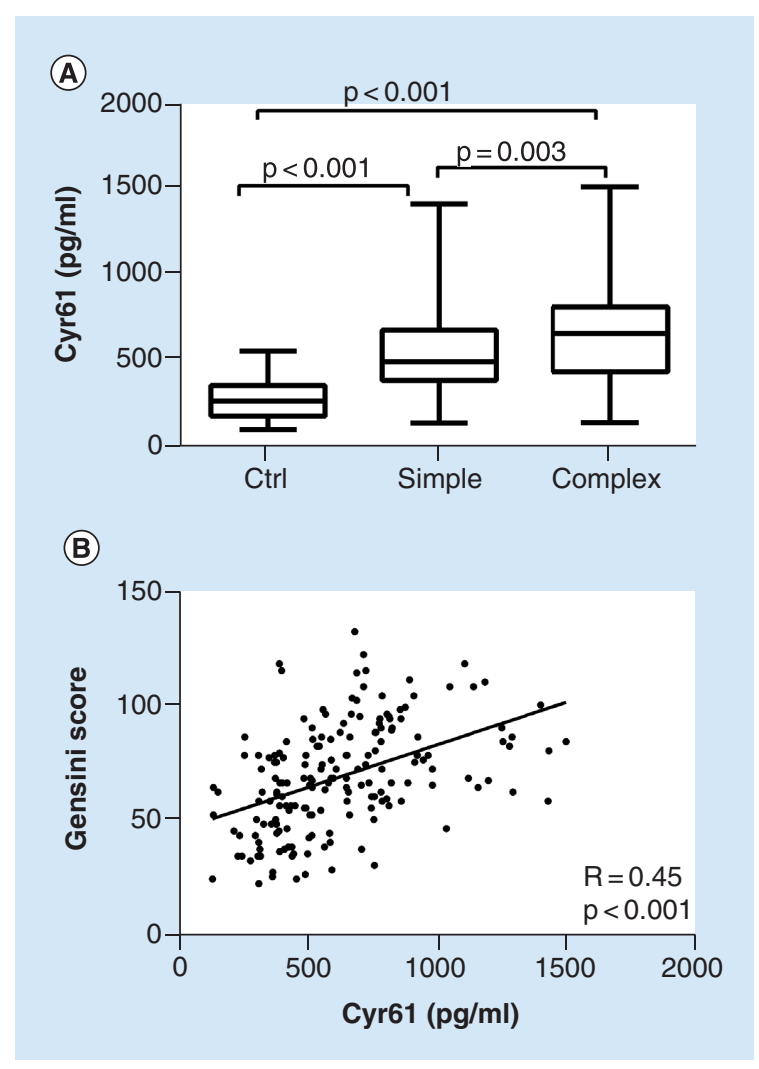

Figure 2. Association of serum Cyr61 with the severity of atherosclerostic lesions. (A) Serum Cyr61 levels in patients with complex lesions were significantly increased compared with those with simple lesions. (B) Serum Cyr61 levels were positively correlated with Gensini score in patients with CAD. CAD: Coronary artery disease; Ctrl: Control.

\section{Association of serum Cyr61 with coronary lesion severity}

To exam the association of Cyr61 levels with the severity of coronary atherosclerosis, patients were classified into two groups: simple lesion and complex lesion. As shown in Figure 2A, serum Cyr61 levels were significantly higher both in the simple lesion $(531.1 \pm 238.92 \mathrm{pg} / \mathrm{ml})$ and complex lesion $(662.04 \pm 293.68 \mathrm{pg} / \mathrm{ml})$ groups compared with those in Ctrl group $(265.26 \pm 116.70 \mathrm{pg} / \mathrm{ml})$, and serum Cyr61 levels in patients with complex lesion were significantly higher compared with those with simple lesion $(662.04 \pm 293.68$ vs $531.1 \pm 238.92 \mathrm{pg} / \mathrm{ml}$; $\mathrm{p}=0.003)$. Spearman correlation analyses showed a positive correlation between serum Cyr61 levels and Gensini score $(\mathrm{r}=0.45 ; \mathrm{p}<0.001)$ (Figure 2B).

\section{Association of serum Cyr61 with hs-CRP \& ROC curve analysis}

CRP is not only a useful biomarker, but also an independent risk factor for CAD pathogenesis. Consistent with other studies, we found hs-CRP levels were significantly elevated in CAD group than that in Ctrl group $(\mathrm{p}=0.01)$ and hs-CRP levels in ACS (including UAP and AMI) group were significantly higher than that in SAP group $(\mathrm{p}<0.001)$ (Table 1). Since both serum levels of Cyr61 and hs-CRP were elevated significantly in CAD group in our study, we analyzed the correlation of serum Cyr61 with hs-CRP levels using Spearman's correlation analysis. As shown in Figure 3A, a significant correlation between these two parameters was demonstrated in CAD group $(\mathrm{r}=0.59 ; \mathrm{p}<0.001)$, but no correlation in the Ctrl group $(\mathrm{r}=0.19 ; \mathrm{p}=0.11$; data not shown).

ROC curve analyses were carried out to evaluate the diagnostic value of serum Cyr61 as biomarker to differentiate patients with or without CAD. ROC curve analyses showed the area under the curve (AUC) for serum Cyr61 was 0.90 (95\% CI: 0.861-0.937; $\mathrm{p}<0.001$ ) and AUC for hs-CRP was 0.91 (95\% CI: 0.888-0.951; $\mathrm{p}<0.001$ ) (Figure 3B), indicating excellent accuracy as hs-CRP had. The ability of the area under the ROC curve based on serum Cyr61 levels to predict the presence of CAD was 0.90. The optimal cutoff values of serum Cyr61 level were $365.7 \mathrm{pg} / \mathrm{ml}(84.44 \%$ sensitivity and $81.08 \%$ specificity) to detect CAD. There was no significant difference in comparison of ROC curves of Cyr61 with hs-CRP by z-test. 
Figure 3. Relationship of serum Cyr61 with CRP. (A) Serum Cyr61 levels were positively correlated with hs-CRP in patients with CAD. (B) ROC curves of Cyr61 and hs-CRP for the identification of CAD. AUC for Cyr61 0.90 (95\% Cl: 0.861-0.937; $p<0.001$ ) and for hs-CRP 0.91 (95\% Cl: 0.888-0.951; $p<0.001)$.

AUC: Area under the curve; CAD: Coronary artery disease; hs-CRP: High sensitivity C-reactive protein; ROC: Receiver operating characteristic.
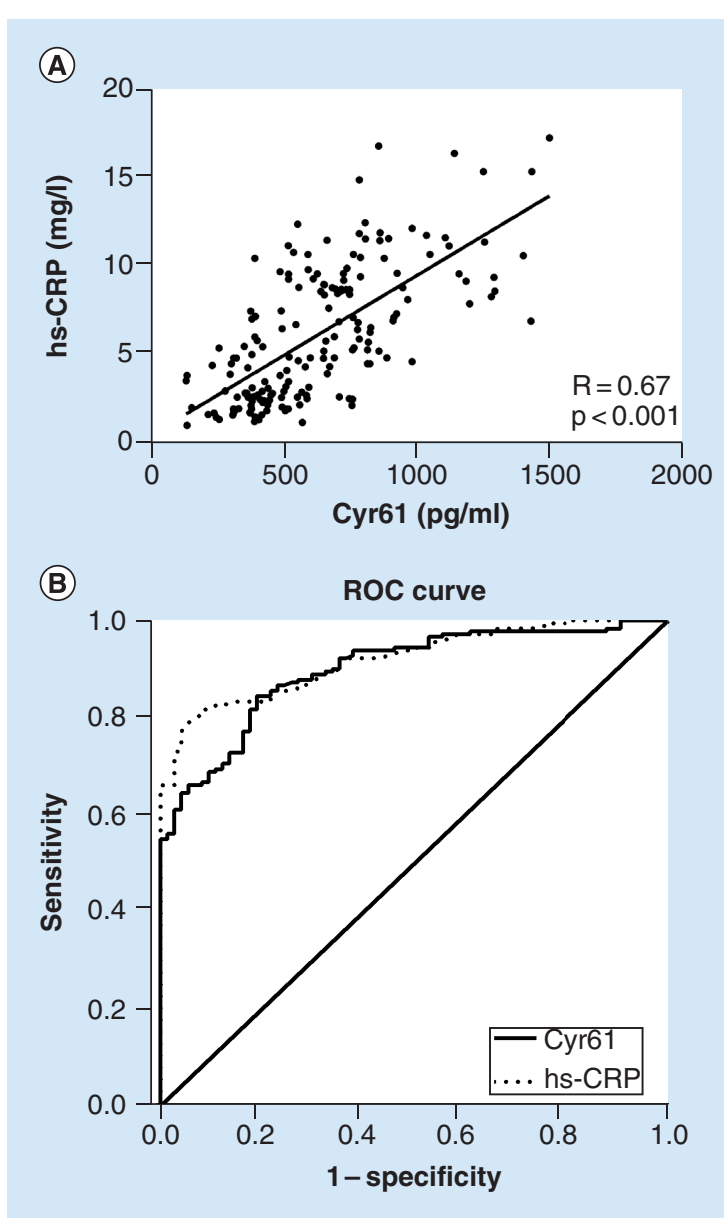

\section{Table 2. Serum levels of Cyr61 in each groups and subgroups.}

\section{Characteristic}

Characteristic

Male 52

Female 22

HTN 15

Normal BP

DM 8

Non-DM 66

Smoking 12

Nonsmoking

Dyslipidemia

Normolipidemia

${ }^{\dagger} p=0.045$.

$\ddagger \mathrm{p}=0.028$ versus normal $B P$.

BP: Blood pressure; CAD: Coronary artery disease; Ctrl: Control; DM: Diabetes mellitus; HTN: Hypertension.

Relationship between serum Cyr61 leaves and risk factors

The relationship of serum Cyr61 levels with traditional CAD risk factors, such as gender, cigarette smoking, DM, dyslipidemia and HTN were analyzed. As shown in Table 2, all participants with HTN both in the Ctrl and CAD groups exhibited significant higher serum Cyr61 levels compared with those with normal BP (Ctrl group: $338.45 \pm 163.67$ vs $244.33 \pm 127.45 \mathrm{pg} / \mathrm{ml} ; \mathrm{p}=0.045$; CAD group: $586.25 \pm 270.33$ vs $470.67 \pm 190.56 \mathrm{pg} / \mathrm{ml}$; 
Table 3. Multivariable logistic regression analysis for independent factors of coronary artery disease.

\begin{tabular}{|llll|} 
& OR & $95 \% \mathrm{Cl}$ & $\mathrm{p}$-value \\
\hline Age & 1.04 & $0.82-1.26$ & 0.08 \\
\hline Gender & 0.95 & $0.39-2.32$ & 0.16 \\
\hline BMI & 1.08 & $0.80-1.47$ & 0.21 \\
\hline HTN & 3.17 & $1.58-4.72$ & 0.02 \\
\hline DM & 1.96 & $1.55-3.92$ & 0.02 \\
\hline Smoking & 1.76 & $1.11-4.83$ & 0.01 \\
\hline LDL & 2.45 & $1.09-2.54$ & 0.04 \\
\hline HDL & 1.05 & $0.75-1.78$ & 0.09 \\
\hline Uric acid & 1.16 & $0.79-2.06$ & 0.06 \\
\hline hs-CRP & 2.06 & $1.18-5.75$ & 0.02 \\
\hline Cyr61 & 1.65 & $1.48-3.92$ & 0.01 \\
\hline BMI: Body mass index; DM: Diabetes mellitus; HDL: High-density lipoprotein; hs-CRP: High sensitivity C-reactive protein; HTN: Hypertension; LDL: Low-density lipoprotein; OR: Odds ratio.
\end{tabular}

$\mathrm{p}=0.028)$, but there were no significant differences in serum Cyr61 levels in association with gender, smoking, dyslipidemia and DM either in Ctrl or CAD groups.

\section{Multivariable logistic regression analyses}

To evaluate the independent predictors of the presence of $\mathrm{CAD}$, multivariable logistic regression analyses were performed to assess their independent contribution to CAD presence. The results (Table 3) show that serum Cyr61 levels were independently correlated with the existence of CAD (odds ratio: 1.85; 95\% CI: 1.48-3.92; $\mathrm{p}=0.01$ ). In addition, HTN, DM, cigarette smoking, low-density lipoprotein and hs-CRP were also significantly associated with the existence of CAD.

\section{Discussion}

In this study, we first demonstrated that serum Cyr61 levels are significantly elevated in patients with CAD, especially with ACS, than in those without CAD. Positive correlations are observed between serum Cyr61 levels and hs-CRP or Gensini score in CAD patients. In addition, multivariable logistic regression analyses demonstrated that elevated serum Cyr61 level is an independent predictor of CAD presence. Those findings suggest that $\mathrm{Cyr} 61$ play an important role in pathogenesis and development of CAD and serum Cyr61 level may serve as a biomarker in diagnosis, risk assessment and therapeutic target for CAD.

Cyr61 play important roles in inflammation, wound healing and tissue remodeling including atherosclerosis [3,911]. Studies demonstrated that Cyr61 is increased after vascular injury and higher level of Cyr61 is reported in atherosclerostic lesions [12-14]. The expression of Cyr61 is at a very low level in quiescent condition, but is highly expressed within minutes or hours after stimulation by numerous atherogenic factors or extracellular stimuli including VEGF, PDGF, bFGF, TGF- $\beta$, growth hormone, angiotensin II, thrombin, inflammatory cytokines, hs-CRP and hypoxia, mechanical stretch $[15,18-30]$. A variety of cell types including endothelial and epithelial cells, vascular smooth muscle cells, fibroblasts, monocytes, activated platelets and cardiomyocytes have been identified as sources of Cyr61 [11-16,18,28,31]. In addition, disturbed shear stress and mechanical stretch on vessel wall also contributes to Cyr61 secretion into circulation [26,32]. Therefore, it is plausible that these cells activated by numerous atherogenic factors mentioned above express and secrete Cyr61 into circulation resulting in elevated serum Cyr61 in patients with CAD. On the other hand, Cyr61 is recognized as a mediator of inflammation [33,35]. Cyr61 enables monocytes recruitment upon vascular inflammation, and endothelial-bound Cyr61 sustains monocyte patrolling under inflammation condition, while blocking Cyr61, impairs early arrival of monocyte and abolishes neutrophil recruitment [34]. Other studies showed that Cyr61 promotes monocyte chemotaxis and macrophage migration, support macrophage adhesion and activates proinflammatory genetic program by activating NFKB-mediated transcription, and upregulating expression of cytokines and chemokines in macrophages [35,36], indicating an important role of Cyr61 in inflammatory responses and its essential role in atherosclerostic pathogenesis. The initial and key step for atherogenesis is endothelial inflammation and leukocytes recruitment and infiltration [37], thus, elevated serum Cyr61 levels in patients with CAD is consistent with the concept of inflammatory mechanisms in atherosclerosis pathogenesis and reflects atherosclerosis development and progression. In addition, Cyr61 was reported to support 
vascular smooth muscle cells (VSMCs) adhesion and stimulate proliferation and migration [19,38], this effect may also involve the recruitment of VSMCs from the tunica media into the tunica intima to accelerate atheroma formation and vascular narrowing. Therefore, Cyr61 may be implicated in different stage of atherosclerosis. Indeed, from multivariable logistic regression analyses, we found that serum Cyr61 levels were independently correlated with the existence of CAD suggesting Cyr61 as an atherogenic factor. In this study, we also evaluated the association of elevated serum Cyr61 with clinical severity in patients with CAD, and found that patients with complex atherosclerostic lesions had higher levels of serum Cyr61 compared with those with simple lesions, and serum Cyr61 levels were found to be positively correlated with Gensini score in CAD patients, indicating the clinical significance of serum Cyr61 level to predict atherosclerostic severity and progression.

The observation that patients with ACS have significantly higher levels of serum Cyr61 than that in SAP patients indicates Cyr61 is a hallmark of unstable plaque and implicated in the occurrence or development of ACS. Not only circulating in bloodstream, but Cyr61 also deposits in tissues including vessel wall, participating in inflammation, vasa vasorum angiogenesis and vascular remodeling [9]. It is well documented that inflammation, platelet activation, plaque rupture and mural thrombosis formation are the main events to trigger ACS [44]. Macrophages activation and releasing lytic enzymes contribute significantly to the rupture of plaque. Platelet activation and granule release amplifies thrombus formation at sites of vascular injury and plays critical role in ACS. Hviid et al. demonstrated platelets activated by thrombin release Cyr61 [31]. We also found that Cyr61 stimulates matrix metalloproteinase-2 expression through $\alpha_{\mathrm{v}} \beta_{3}$ integrin in VSMCs [DENG, UNPUBLISHED DATA], which is highly expressed in vulnerable regions of human atherosclerotic plaques and contribute to plaque vulnerability. Jedsadayanmata $e t$ al. [39] reported that activated platelets adhere to Cyr61 through integrin $\alpha_{\mathrm{II}} \beta_{3}$ which may contribute to the stability of the hemostatic plug and the tight adhesion of platelets to the subendothelial matrix suggesting a functional role in hemostasis and thrombosis. The finding by Klingenberg et al. [49] that Cyr61 expression is markedly increased in coronary thrombi aspirated from the infarct-related coronary artery in ACS patients also supports a role of Cyr61 in thrombosis. In addition, Cyr61 was demonstrated to bind integrins $\alpha_{v} \beta_{3}$ and $\alpha_{6} \beta_{1}$ to mediate endothelial cell adhesion, migration, angiogenesis and neovascularization [40], the angiogenic effects of Cyr61 may contribute to the formation of hemorrhagic neovessels in the intima of vulnerable plaques leading to intraplaque hemorrhages and increase in plaque vulnerability to rupture. Considering those above, higher levels of serum Cyr61 may contribute significantly to ACS progression through diverse mechanisms. Although not statistically significant, serum Cyr61 levels were higher in patients with AMI than those with UAP in our study, this suggests a sustained elevation of serum Cyr61 in ACS and a sign of prelude of aggravation of UAP leading to AMI occurrence, implying a role of Cyr61 in the increased cardiovascular events. On the other hand, high levels of serum Cyr61 in ACS patients may also reflect the severity of myocardial ischemia since Cyr61 expression is strongly induced in both ischemic and remote left ventricular myocardium $[15,49]$.

Analyses of the data revealed a positive correlation between serum Cyr61 and hs-CRP levels in patients with CAD. Not only an inflammation biomarker, but also CRP associates with atherosclerosis progression and cardiovascular risk as an atherogenic factor [42]. CRP is reported to increase Cyr61 mRNA in endothelial cells [28], and Cyr61 increases the expression of IL- 6 in macrophages through integrin $\alpha \mathrm{M} \beta 2$ and in fibroblasts through $\alpha 6 \beta 1$ [41], an important cytokine to control CRP synthesis mainly in the liver, therefore, a synergistic effect exists in Cyr61 with CRP of their production, which reinforces the notion of inflammatory effect of Cyr61 on CAD. Moreover, ROC curve analyses showed the AUC of Cyr61 (AUC $=0.90 ; 95 \%$ CI: 0.855-0.945; $\mathrm{p}<0.001$ ) is similar as hs-CRP $(\mathrm{AUC}=0.91 ; 95 \%$ CI: $0.876-0.955 ; \mathrm{p}<0.001)$ in trends without statistical difference between them, indicating serum Cyr61 level had excellent performance in diagnosis for CAD. CRP is an acute phase reactant and its secretion begins within $4-6 \mathrm{~h}$ of the stimulus and peaks at about 36-48 h. CRP is widely used and recognized as valuable biomarker in cardiovascular risk and events assessment. As an inducible immediate early gene, Cyr61 syntheses is increased by numerous atherogenic factors maximally at $1-3 \mathrm{~h}[13,19,26,30,43]$, we found Cyr61 is significantly increased maximally at $2 \mathrm{~h}$ with lasting more than $8 \mathrm{~h}$ in high level after stimulation by angiotensin II and thrombin in human aortic smooth muscle cells [DENG, UNPUBLISHED DATA], indicating the change of Cyr61 precedes CRP in rise and peaking. Therefore, $\mathrm{Cyr} 61$ holds promising value as a biomarker candidate in CAD diagnosis, risk stratification and monitoring therapeutic efficacy and prognosis than CRP does.

It is well known that renin-angiotensin system activation and increase in peripheral vascular resistance plays an important role in pathogenesis of HTN. Arterial stiffness due to alterations in extracellular matrix in vascular wall is one of the mechanisms for increased peripheral resistance in HTN [48]. Cyr61 was reported to be induced rapidly by Ang II in vascular cells and tissue [45,46]. BP is largely responsible for mechanical stretch on the blood 
vessel wall, while mechanical stretch increases Cyr61 expression in smooth muscle cells [26,47]. In this study, we first observed that participants with HTN both in CAD and Ctrl groups have significant higher levels of serum Cyr61. Such levels could associate with renin-angiotensin system activation and mechanical stretch by high BP. Cyr61 supports VASMC adhesion and stimulates VASMC migration, proliferation [38] and participates in vascular remodeling, thus, high levels of Cyr61 may alter VASMC and arterial stiffness and be implicated in the pathogenesis or progression of HTN. We did not evaluate the correlation between BP reading and serum Cyr61 levels in this study. Further studies are needed to investigate the reciprocal effects of HTN with Cyr61 level change and the mechanism of Cyr61 in HTN pathogenesis.

\section{Conclusion \& future perspective}

In summary, we reported the first study regarding the serum Cyr61 levels and its clinical significance in CAD patients. Our results showed that serum Cyr61 levels were increased in patients with CAD, especially with complex lesions and ACS, and positively correlated with hs-CRP, Gensini score in patients with CAD. Based on the findings, our study support the notion that serum Cyr61 levels hold the promise as a biomarker in diagnosing and characterizing $\mathrm{CAD}$ as well as risk stratification and therapeutic target for CAD.

There are some limitations in the study: this is a single-center study with small size in each group, large scale or multicenter clinical study is recommended to clarify the significance of serum Cyr61 levels in CAD; serum Cyr61 levels were only analyzed at one single time point, and we did not analyze inter- and intra-assay coefficients of variability of Cyr61 in this study. Kinetic analyses with multiple time points and triplicate measurement of serum Cyr61 levels may provide more valuable information. Finally, future studies are warranted to evaluate the association of serum Cyr61 levels with Framingham risk score as well as cardiovascular events.

\section{Executive summary}

- This study investigated serum Cysteine-rich protein 61 (Cyr61) levels in patients with coronary artery disease (CAD).

- 180 patients with CAD and 74 participants without CAD were enrolled randomly in this study. Serum Cyr61 levels and high-sensitivity C-reactive protein (hs-CRP) were measured using commercially available enzyme-linked immunosorbent assay kits. Gensini scores were calculated to evaluate the severity of coronary atherosclerotic lesions.

- Results of data analyzed show that serum Cyr61 levels were significantly higher in patients with CAD than in those without CAD.

- Patients with acute coronary syndrome (ACS) had significantly higher Cyr61 levels than those with stable angina pectoris (SAP).

- Serum Cyr61 levels in complex lesion group were significantly higher than in simple one.

- Serum Cyr61 was positively correlated with hs-CRP and Gensini score.

- Area under receiver operation characteristic (ROC) curve analysis showed a sensitivity of $84.44 \%$ and specificity of $81.08 \%$ at the optimal cutoff point of serum Cyr61 level $365.7 \mathrm{pg} / \mathrm{ml}$.

- Multivariable logistic regression analyses demonstrated that serum Cyr61 levels were independently correlated with the existence of CAD.

- In conclusion, serum Cyr61 levels are increased in patients with CAD, especially in patients with ACS, and show significant correlation with the severity of CAD, suggesting Cyr61 as a potential biomarker in characterizing and stratifying $C A D$ as well as a therapeutic target for CAD.

\section{Acknowledgements}

The authors appreciate Dr Jianhua Huang at Division of Cardiology, Duke University Medical Center for his critical advice and revision of this study.

Financial \& competing interests disclosure

The authors have no relevant affiliations or financial involvement with any organization or entity with a financial interest in or financial conflict with the subject matter or materials discussed in the manuscript. This includes employment, consultancies, honoraria, stock ownership or options, expert testimony, grants or patents received or pending, or royalties.

No writing assistance was utilized in the production of this manuscript. 


\section{Ethical conduct of research}

The authors state that this study was approved by the ethics committee of the authors' hospitals, and the authors have followed the principles outlined in the Declaration of Helsinki for all human or animal experimental investigations. In addition, for investigations involving human subjects, informed consent has been obtained from each participant involved.

\section{Open access}

This work is licensed under the Attribution-NonCommercial-NoDerivatives 4.0 Unported License. To view a copy of this license, visit http://creativecommons.org/licenses/by-nc-nd/4.0/

\section{References}

Papers of special note have been highlighted as: $\bullet$ of interest; $\bullet \bullet$ of considerable interest

1 Murphy-Ullrich JE, Sage EH. Revisiting the matricellular concept. Matrix Biol. 37, 1-14 (2014).

2 Viloria K, Hill NJ. Embracing the complexity of matricellular proteins: the functional and clinical significance of splice variation. Biomol. Concepts 7, 117-132 (2016).

3 Jun JI, Lau LF. Taking aim at the extracellular matrix: CCN proteins as emerging therapeutic targets. Nat. Rev. Drug Discov. 10, 945-963 (2011).

4 Bornstein P, Sage EH. Matricellular proteins: extracellular modulators of cell function. Curr. Opin. Cell Biol. 14, 608-616 (2002).

5 Schellings MW, Pinto YM, Heymans S. Matricellular proteins in the heart: possible role during stress and remodeling. Cardiovasc. Res. 64, 24-31 (2004).

6 Matsui Y, Morimoto J, Uede T. Role of matricellular proteins in cardiac tissue remodeling after myocardial infarction. World J. Biol. Chem. 1, 69-80 (2010).

7 Frangogiannis NG. Matricellular proteins in cardiac adaptation and disease. Physiol. Rev. 92, 635-688 (2012).

8 Okamoto H, Imanaka-Yoshida K. Matricellular proteins: new molecular targets to prevent heart failure. Cardiovasc. Ther. 30, e198-e209 (2012).

9 Lau LF. CCN1/CYR61: the very model of a modern matricellular protein. Cell. Mol. Life Sci. 68, 3149-3163 (2011).

10 Chen CC, Lau LF. Functions and mechanisms of action of CCN matricellular proteins. Int. J. Biochem. Cell. Biol. 41, 771-783 (2009).

11 Emre Y, Imhof BA. Matricellular protein CCN1/CYR61: a new player in inflammation and leukocyte trafficking. Semin. Immunopathol. 36, 253-259 (2014).

12 Matsumae H, Yoshida Y, Ono K et al. CCN1 knockdown suppresses neointimal hyperplasia in a rat artery balloon injury model. Arterioscler. Thromb. Vasc. Biol. 28, 1077-1083 (2008).

13 Schober JM, Chen N, Grzeszkiewicz TM et al. Identification of integrin alpha(M)beta(2) as an adhesion receptor on peripheral blood monocytes for Cyr61 (CCN1) and connective tissue growth factor (CCN2): immediate-early gene products expressed in atherosclerotic lesions. Blood 99, 4457-4465 (2002).

-. Demonstrates that Cyr61 is highly expressed in advanced atherosclerotic lesions of apolipoprotein E-deficient mice, and monocytes adhere to Cyr61 in an activation-dependent manner mediated through integrin alpha(M)beta(2), indicating Cyr61 in atherosclerosis pathogenesis.

14 Hilfiker A, Hilfiker-Kleiner D, Fuchs $\mathrm{M}$ et al. Expression of CYR61, an angiogenic immediate early gene, in arteriosclerosis and its regulation by angiotensin II. Circulation 106, 254-260 (2002).

-. This is the first observation that CYR61 expression is higher within connective tissue in neointima, adventitia and surrounding small capillaries and blood vessels, co-localized with angiotensin-converting enzyme and Ang II in human carotid atherectomies and arteriosclerotic coronary arteries, suggesting the effect of $\mathrm{Cyr} 61$ in contribution to plaque neovascularization by enhancing regulators of microvessel formation.

15 Hilfiker-Kleiner D, Kaminski K, Kaminska A et al. Regulation of proangiogenic factor CCN1 in cardiac muscle: impact of ischemia, pressure overload and neurohumoral activation. Circulation 109, 2227-2233 (2004).

16 Papetta A, Gakiopoulou H, Agapitos E, Patsouris ES, Lazaris AC. Correlations between CCN1 immunoexpression and myocardial histologic lesions in sudden cardiac death. Am. J. Forensic Med. Pathol. 34, 169-176 (2013).

17 Gensini GG. A more meaningful scoring system for determining the severity of coronary artery disease. Am. J. Cardiol. 51, 606 (1983).

18 Abe M, Sato Y. cDNA microarray analysis of the gene expression profile of VEGF-activated human umbilical vein endothelial cells. Angiogenesis 4, 289-298 (2001).

19 Zhang F, Hao F, An D et al. The matricellular protein Cyr61 is a key mediator of platelet-derived growth factor-induced cell migration. J. Biol. Chem. 290, 8232-8242 (2015).

20 Parisi MS, Gazzerro E, Rydziel S, Canalis E. Expression and regulation of CCN genes in murine osteoblasts. Bone 38, 671-677 (2006). 
21 Sampath D, Winneker RC, Zhang Z. Cyr61, a member of the CCN family, is required for MCF-7 cell proliferation: regulation by 17beta-estradiol and over-expression in human breast cancer. Endocrinology 142, 2540-2548 (2001).

22 Mo F-E, Muntean AG, Chen C-C et al. CYR61 (CCN1) is essential for placental development and vascular integrity. Mol. Cell Biol. 22, 8709-8720 (2002).

23 Hammacher A, Thomnpson EW, Williams ED. Interleukin-6 is a potent inducer of S100P, which is up-regulated in androgen-refractory and metastatic prostate cancer. Int. J. Biochem. Cell. Biol. 37, 442-450 (2005).

24 Rivera-Gonzalez R, Petersen DN, Tkalcevic G et al. Estrogen-induced genes in the uterus of ovariectomized rats and their regulation by droloxifene and tamoxifen. J. Steroid Biochem. Mol. Biol. 64, 13-24 (1998).

25 Pendurthi UR, Allen KE, Ezban M et al. Factor VIIa and thrombin induce the expression of Cyr61 and VIIa and thrombin induce the expression of Cyr61 and connective tissue growth factor, extracellular matrix signaling proteins that could act as possible downstream mediators in factor VIIa x tissue factor-induced signal transduction. J. Biol. Chem. 275, 14632-14641 (2000).

26 Grote K, Bavendiek U, Grothusen C et al. Stretch-inducible expression of the angiogenic factor CCN1 in vascular smooth muscle cells is mediated by Egr-1. J. Biol. Chem. 279, 55675-55681 (2004).

27 Brigstock DR. The CCN family: a new stimulus package. J. Endocrinol. 178, 169-175 (2003).

28 Turu MM, Slevin M, Matou S et al. C-reactive protein exerts angiogenic effects on vascular endothelial cells and modulates associated signalling pathways and gene expression. BMC Cell Biol. 9, 47 (2008).

29 Kunz M, Moeller S, Koczan D et al. Mechanisms of hypoxic gene regulation of angiogenesis factor Cyr61 in melanoma cells. J. Biol. Chem. 278, 45651-45660 (2003).

30 Walsh CT, Radeff-Huang J, Matteo R et al. Thrombin receptor and RhoA mediate cell proliferation through integrins and cysteine-rich protein 61. FASEB J. 22, 4011-4021 (2008).

31 Hviid CV, Samulin Erdem J, Drechsler S et al. The matricellular 'cysteine-rich protein 61' is released from activated platelets and increased in the circulation during experimentally induced sepsis. Shock 41, 233-240 (2014).

32 Chaqour B, Goppelt-Struebe M. Mechanical regulation of the Cyr61/CCN1 and CTGF/CCN2 proteins. FEBS J. 273, 3639-3649 (2006).

33 Emre Y, Imhof BA. Matricellular protein CCN1/CYR61: a new player in inflammation and leukocyte trafficking. Semin. Immunopathol. 36, 253-259 (2014).

34 Imhof BA, Jemelin S, Ballet R et al. CCN1/CYR61-mediated meticulous patrolling by Ly6Clow monocytes fuels vascular inflammation. Proc. Natl Acad. Sci. USA 113, E4847-E4856 (2016).

- Demonstrated that Cyr61 is released by activated platelets and enables the recruitment of monocytes upon vascular inflammation, and endothelium-bound Cyr61 sustains the adequate patrolling of monocytes as an inflammatory mediator.

35 Löbel M, Bauer S, Meisel C et al. CCN1: a novel inflammation-regulated biphasic immune cell migration modulator. Cell. Mol. Life Sci. 69, 3101-3113 (2012).

36 Bai T, Chen CC, Lau LF. Matricellular protein CCN1 activates a proinflammatory genetic program in murine macrophages. J. Immunol. 184, 3223-3232 (2010).

37 Libby P. Inflammation in atherosclerosis. Nature 420, 868-874 (2002).

38 Grzeszkiewicz TM, Lindner V, Chen N, Lam SC, Lau LF. The angiogenic factor cysteine-rich 61 (CYR61, CCN1) supports vascular smooth muscle cell adhesion and stimulates chemotaxis through integrin alpha(6)beta(1) and cell surface heparan sulfate proteoglycans. Endocrinology 143, 1441-1450 (2002).

39 Jedsadayanmata A, Chen CC, Kireeva ML, Lau LF, Lam SC. Activation-dependent adhesion of human platelets to Cyr61 and Fisp12/mouse connective tissue growth factor is mediated through integrin alpha(IIb)beta(3). J. Biol. Chem. 274, 24321-24327 (1999).

40 Leu SJ, Lam SC, Lau LF. Pro-angiogenic activities of CYR61 (CCN1) mediated through integrins alphavbeta3 and alpha6beta1 in human umbilical vein endothelial cells. J. Biol. Chem. 277, 46248-46255 (2002).

41 Choi JS, Kim KH, Lau LF. The matricellular protein CCN1 promotes mucosal healing in murine colitis through IL-6. Mucosal Immunol. 8, 1285-1296 (2015).

42 Szmitko PE, Wang CH, Weisel RD, de Almeida JR, Anderson TJ, Verma S. New markers of inflammation and endothelial cell activation: Part I. Circulation 108, 1917-1923 (2003).

43 Han JS, Macarak E, Rosenbloom J, Chung KC, Chaqour B. Regulation of Cyr61/CCN1 gene expression through RhoA GTPase and p38MAPK signaling pathways. Eur. J. Biochem. 270, 3408-3421 (2003).

44 Falk E, Nakano M, Bentzon JF, Finn AV, Virmani R. Update on acute coronary syndromes: the pathologists' view. Eur. Heart J. 34 , 719-728 (2013).

45 Gao BB, Stuart L, Feener EP. Label-free quantitative analysis of one-dimensional PAGE LC/MS/MS proteome: application on angiotensin II-stimulated smooth muscle cells secretome. Mol. Cell. Proteomics 7, 2399-409 (2008).

46 Lee HY, Chung JW, Youn SW et al. Forkhead transcription factor FOXO3a is a negative regulator of angiogenic immediate early gene CYR61, leading to inhibition of vascular smooth muscle cell proliferation and neointimal hyperplasia. Circ. Res. 100, 372-380 (2007). 
47 Yang R, Amir J, Liu H, Chaqour B. Mechanical strain activates a program of genes functionally involved in paracrine signaling of angiogenesis. Physiol. Genomics 36, 1-14 (2008).

48 Briones AM, Arribas SM, Salaices M. Role of extracellular matrix in vascular remodeling of hypertension. Curr. Opin. Nephrol. Hypertens. 19, 187-194 (2010).

49 Klingenberg R, Aghlmandi S, Liebetrau C et al. Cysteine-rich angiogenic inducer 61 (Cyr61): a novel soluble biomarker of acute myocardial injury improves risk stratification after acute coronary syndromes. Eur. Heart J. 38(47), 3493-3502 (2017).

- This is the first observation of serum Cyr61 in patients with acute coronary syndrome published online after our draft was submitted. The study evaluated serum Cyr61 as a novel biomarker involved in the early events leading to an acute coronary syndrome and evaluate its role in diagnosis and risk stratification. 
